Tropical Journal of Pharmaceutical Research July 2017; 16 (7): 1675-1682

ISSN: $1596-5996$ (print); 1596-9827 (electronic)

(C) Pharmacotherapy Group, Faculty of Pharmacy, University of Benin, Benin City, 300001 Nigeria.

All rights reserved.

Available online at http://www.tjpr.org

Original Research Article

http://dx.doi.org/10.4314/tjpr.v16i7.28

\title{
Solid phase extraction method for determination of mitragynine in urine and its application to mitragynine excretion study in rats receiving caffeine
}

\author{
Sathaporn Prutipanlai ${ }^{1 *}$, Ornchuma Botpiboon ${ }^{2,3}$, Benjamas Janchawee ${ }^{1,4}$, \\ Sittipoom Theanchaiwattana ${ }^{5}$ \\ ${ }^{1}$ Department of Pharmacology, ${ }^{2}$ Department of Applied Science, ${ }^{3}$ Police Forensic Science Center 10, Yala 95000, ${ }^{4}$ Natural \\ Products Research Center, Faculty of Science, Prince of Songkla University, Songkhla 90112, ${ }^{5}$ Police Forensic Science Center \\ 9, Songkhla 90110, Thailand
}

*For correspondence: Email: sataporn.p@psu.ac.th; Tel: +66-74288183

Sent for review: 20 November 2016

Revised accepted: 15 June 2017

\begin{abstract}
Purpose: To develop a solid phase extraction (SPE) method that utilizes reverse-phase high performance liquid chromatography (RP-HPLC) to determine mitragynine (MG) in rat and human urine, and to investigate the influence of caffeine (CF) on urinary excretion of $M G$ in rats.

Methods: A two-dimensional wash-elute study was conducted using Oasis $B^{3}$ HLB cartridge. The optimized SPE procedures consisted of washing with 5 and $70 \%$ methanol containing $2 \%$ ammonium hydroxide and eluting with methanol containing $2 \%$ acetic acid. The SPE-HPLC method was validated according to United States Food and Drug Administration guidelines. Two groups of rats were used for the study and received an oral administration of either alkaloid extract (AE) of kratom (100 mg/kg), or AE $(100 \mathrm{mg} / \mathrm{kg})$ combined with CF $(25 \mathrm{mg} / \mathrm{kg})$. The 24-h urine samples after administration were analyzed using the developed method for the content of MG excreted.

Results: Validation indicate good linearity ( $r>0.9991)$ and high precision in rat $(1.18-5.97)$ and human urine (0.67 - 3.41). Accuracy for rat and human urine ranged from $-9.11-19.64$ and $-7.20-13.72 \%$, respectively. Recovery of MG ranged from 92.75 - $100.83 \%$. Co-administration of $A E$ and CF significantly increased urinary excretion of $M G$.

Conclusion: The developed SPE method is simple, fast and reliable, and can be suitably applied to pharmacokinetic studies
\end{abstract}

Keywords: Mitragynine, Mitragyna speciosa, Solid phase extraction, Caffeine, Urine

Tropical Journal of Pharmaceutical Research is indexed by Science Citation Index (SciSearch), Scopus, International Pharmaceutical Abstract, Chemical Abstracts, Embase, Index Copernicus, EBSCO, African Index Medicus, JournalSeek, Journal Citation Reports/Science Edition, Directory of Open Access Journals (DOAJ), African Journal Online, Bioline International, Open-J-Gate and Pharmacy Abstracts

\section{INTRODUCTION}

Kratom (Mitragyna speciosa Korth.) is a native plant in Southeast Asian countries including Thailand. Leaves from kratom have been traditionally used for curing conditions such as diarrhea and muscle pain. It possesses psychoactive properties and opium-like effects [1]. In Thailand, kratom use is illegal as it is arranged in Category V of the Narcotics Act B.E.
2522 (1979). Kratom abuse is common in southern Thailand among adolescents for recreation [2]. A common form of ingestion is a self-prepared ' 4 × 100' cocktail which composes of boiled leaf extract, cola drinks, and codeine cough mixture. The other additives include anxiolytic, antidepressant, and analgesic drugs, mosquito coil powder, fluorescent light bulb powder, road paint, and pesticides. These toxic substances are added with a suggestion for 
enhancing the cocktail's effects without scientific support [3].

Illegal use of kratom can be notified when mitragynine (MG), a major indole alkaloid in kratom leaves, is presented in urine or plasma of suspects. A simple, specific, and sensitive method is needed. To date, several chromatographic techniques for determination of $M G$ in biological matrices have been established. These include gas chromatography coupled with mass spectrometry (GC-MS) [4,5], ultra-high performance liquid chromatography (UHPLC)MS [6,7], LC-MS [8], and LC-MS-MS $[9,10]$. Regarding to the field of bioanalytical research, these sophisticate methods are so sensitive and specific that can replace the ordinary detection systems including HPLC-ultraviolet (UV) detection. In Thailand, GC- and LC-MS were used in most laboratories of governmental agencies responsible for narcotics analytical development and screening.

However, instrument availability is limited by its cost, the HPLC-UV detection with simple and effective sample preparation method is still necessary. This study therefore aimed to develop the simple solid phase extraction (SPE) procedure for determining $M G$ in urine samples. Since several ingredients are present in kratom cocktail, the interaction between MG and other ingredients such as caffeine (CF) has not been reported. This study was also purposed to investigate the effect of CF on urinary excretion of MG in rats. The SPE method developed in this study was applied for sample preparation.

\section{EXPERIMENTAL}

\section{Chemicals}

Methanol (HPLC grade) was from Mallinckrodt Baker Inc., USA. Deionized water was produced by a Milli-Q plus 185 Water Purification System from Millipore corp., USA. Other chemicals were analytical grade.

\section{MG and kratom alkaloid extract}

Leaves of kratom were obtained from the Police Forensic Science Center 9, Songkhla, Thailand, and were extracted to obtain crude alkaloids extract $(A E)$ and $M G$ as previously described [11]. Dried leaves were extracted with methanol followed by chloroform to obtain the AE. The MG was isolated from the $A E$ by using silica gel column chromatography. Then, the MG was identified by mass spectrometer and nuclear magnetic resonance spectroscopy.

\section{Preparation of standard solutions}

Pure methanol was used to prepare a stock solution of $M G(1 \mathrm{mg} / \mathrm{mL})$ which was further diluted to obtain working solutions (0.5-100 $\mu \mathrm{g} / \mathrm{mL}$ ). Calibration standard solutions were prepared by adding working solutions to blank urine samples resulting to the final concentrations of $0.1,0.5,15$ and $10 \mu \mathrm{g} / \mathrm{mL}$.

\section{Chromatographic method}

An Agilent 1200 Series HPLC system coupled with a diode array detector (Agilent, USA) was used. Data were processed using Chemstation Software System Agilent, USA. Chromatography was conditioned as the previous report [11]. Sunfire ${ }^{\mathrm{TM}} \mathrm{C}_{18}(250 \times 4.6 \mathrm{~mm}$ i.d., $5 \mu \mathrm{m})$, a separation column, and Sentry ${ }^{\mathrm{TM}}$ guard columns $(20 \times 4.6 \mathrm{~mm}$ i.d., $5 \mu \mathrm{m})$ from Waters (USA) was equilibrated at $35 \pm 1^{\circ} \mathrm{C}$. Methanol-water mobile phase $(80: 20, v / v)$ was flowed at $0.8 \mathrm{~mL} / \mathrm{min}$. A $20 \mu \mathrm{L}$-aliquot was injected and detected at 225 $\mathrm{nm}$.

\section{Wash-elute study}

Oasis $^{\circledR}$ HLB cartridges $(1 \mathrm{~mL} / 30 \mathrm{mg}$ ) (Waters Corporation, USA) were divided into 2 sets (11 of each) and subjected to passing with methanolwater mixtures $(0,10,20,30,40,50,60,70,80$, 90 and $100 \% \mathrm{v} / \mathrm{v})$ containing either $2 \%$ ammonium hydroxide or $2 \%$ acetic acid as a solvent. The cartridges were preconditioned with methanol and equilibrated with deionized water (1 mL).

Blank- and MG-spiked samples (10 $\mu \mathrm{g} / \mathrm{mL}, 1 \mathrm{~mL})$ $(n=5)$ were loaded. The cartridges were passed with the solvents $(1 \mathrm{~mL})$. The eluate was collected separately and evaporated to dryness at $55{ }^{\circ} \mathrm{C}$ using a CentriVap Concentrator (Labconco, MO, USA). The residue was reconstituted with methanol $(1 \mathrm{~mL})$ for HPLC injection.

\section{Urine sample extraction}

The optimized SPE condition was used for extraction. After precondition and equilibration, the urine samples $(1 \mathrm{~mL})$ were loaded onto the cartridges. The cartridges were washed with 1 $\mathrm{mL}$ of $5 \%$ methanol containing $2 \%$ ammonium hydroxide followed by $1 \mathrm{~mL}$ of $70 \%$ methanol containing $2 \%$ ammonium hydroxide. The analyte was eluted with $1 \mathrm{~mL}$ of $100 \%$ methanol containing $2 \%$ acetic acid. The eluate was collected, evaporated and reconstituted for HPLC analysis. 


\section{Method validation}

Validation was performed to determine linearity, precision, accuracy, recovery, and lower limit of quantification (LLOQ) in accordance with United States of Food and Drug Administration (USFDA) guidelines [12]. Urine of rats and human volunteers $(n=5)$ were used. Peak areaconcentration curve of $M G$ was plotted and subjected to regression analysis to obtain calibration equation and correlation coefficient $(r)$. Precision was indicated as coefficient of variation (CV) and accuracy was shown as deviation (DEV). LLOQ was the lowest concentration measured with acceptable precision and accuracy.

\section{Study of urinary excretion of MG}

\section{Animals}

Adult male Wistar rats $(\mathrm{n}=12,230-250 \mathrm{~g})$ were obtained from the Southern Laboratory Animal Facility, Prince of Songkla University and carried out in accordance with the guidelines of the National Research Council of Thailand based on the International Guiding Principles for Biomedical Research Involving Animals [13]. The study was approved by Animal Ethics Committee, Prince of Songkla University (ref 16/50).

\section{Study protocol}

Two groups of rats (6 each) orally received either a one dose of $A E(100 \mathrm{mg} / \mathrm{kg})$, or AE (100 $\mathrm{mg} / \mathrm{kg}$ ) concomitant with CF $(25 \mathrm{mg} / \mathrm{kg})$. AE was dissolved in pure propylene glycol, while CF was dissolved in deionized water.

(A)

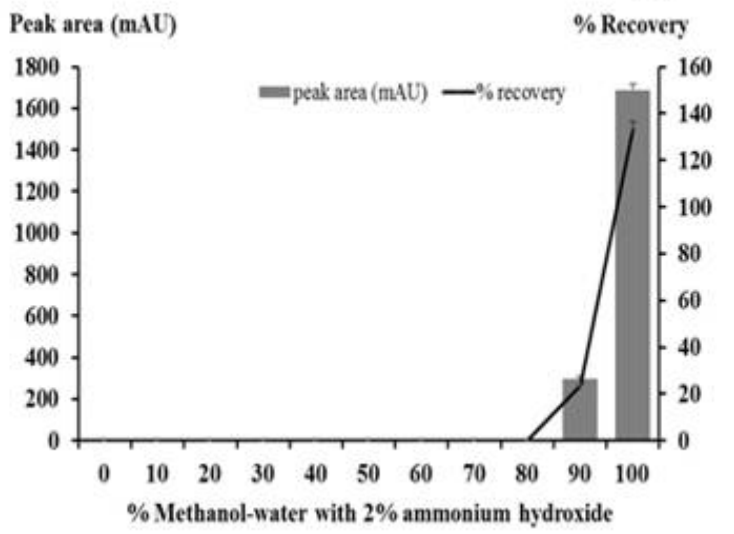

Rats were housed individually in a metabolic cage (Techniplast ${ }^{\circledR}$, USA). Urine was collected 8 $\mathrm{h}$ before and at 8,16 , and $24 \mathrm{~h}$ after drug administration. Samples were centrifuged at $2000 \times \mathrm{g}$ for $15 \mathrm{~min}$ at $4{ }^{\circ} \mathrm{C}$. Supernatant was separated and kept at $-70^{\circ} \mathrm{C}$ until analysis.

\section{Data analysis}

Peak areas, recovery of $M G$ and validation parameters were expressed as mean \pm SD. Percent urinary excretion of $M G$ is expressed as mean \pm SE and compared by Student's t-test. Differences were considered significant at $p<$ 0.05 . As statistical software was used SPSS version 11.50 .

\section{RESULTS}

\section{Wash-elute data}

The efficiency of mobile phase for washing and eluting the cartridges was evaluated based on peak area of MG. When the cartridges were passed with $0-80 \%$ methanol-water mixtures containing $2 \%$ ammonium hydroxide, no $M G$ was eluted (Figure 1A). MG was slightly (23\%) eluted with $90 \%$ methanol-base mixture and mostly with $100 \%$ methanol-base mixture resulting to $133 \%$ recovery of extraction.

In contrast, when the cartridges were passed with $0-40 \%$ methanol-water mixture containing $2 \%$ acetic acid, no MG was detected (Figure 1B). At $50 \%$ and above, MG was progressively eluted reaching the maximum at $90 \%$ methanol mixture. However, the peak of separation was asymmetrical and the recovery was $113 \%$. With $100 \%$ methanol, the peak of separation was symmetrical and the recovery was acceptable (105\%).

(B)

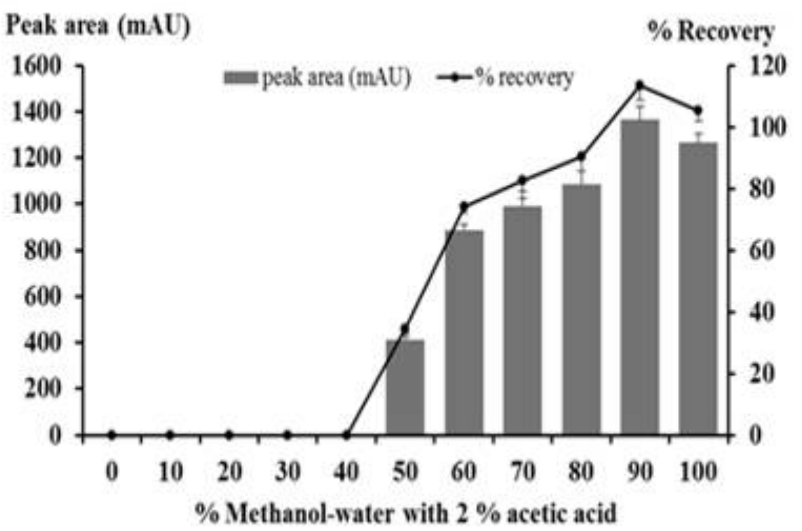

Figure 1: Peak areas and recovery (mean $\pm S D, n=5)$ of $M G$ in rat urine $(10 \mu \mathrm{g} / \mathrm{mL})$ after passing the cartridges with $0-100 \%$ methanol-water mixture with acid-base modification; (A) $2 \%$ ammonium hydroxide; (B) $2 \%$ acetic acid 
The effects of single and double passing of the cartridges with low and high percentages of methanol mixtures containing $2 \%$ ammonium hydroxide were compared. Single passing with 5 $\%$ methanol-base mixture caused many unknown peak interferences (Figure 2A). Single passing with $70 \%$ methanol-base mixture resulted to lesser interferences and sharp peak of MG (Figure 2B). Passing with $5 \%$ methanol-followed by $70 \%$ methanol-base mixture eliminated most interference (Figure 2C). According to the results, the SPE procedure was therefore composed of washing with $5 \%$ methanolfollowed by $70 \%$ methanol-water mixture containing $2 \%$ ammonium hydroxide and eluting with pure methanol containing $2 \%$ acetic acid.

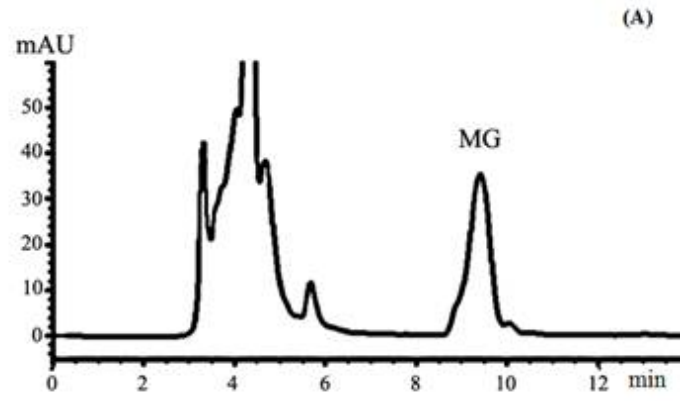

(B)

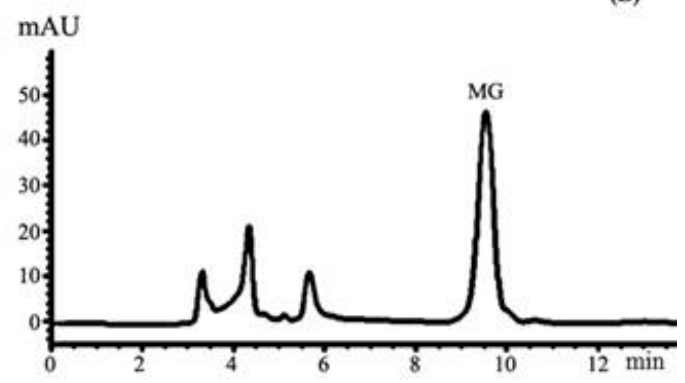

(C)

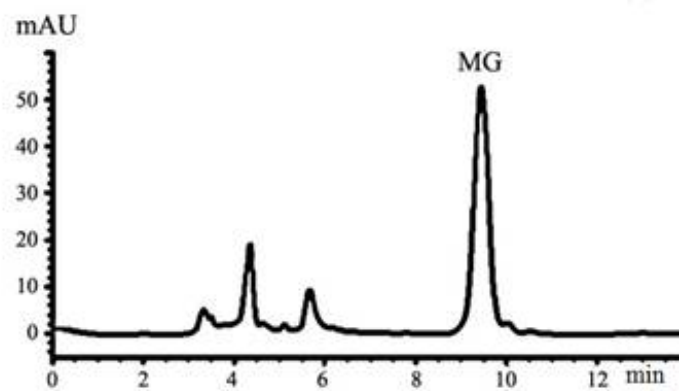

Figure 2: Chromatograms of $M G$ after passing the cartridges with methanol-water mixture containing $2 \%$ ammonium hydroxide; (A) single passing with $5 \%$ methanol; (B) single passing with $70 \%$ methanol; (C) double passing with $5 \%$ followed by $70 \%$ methanol

\section{Extraction of MG in rat and human urine}

MG in rat and human urine was extracted by using SPE technique developed in this study.
MG, clearly separated from other components, was eluted at $9.38 \mathrm{~min}$ and $9.52 \mathrm{~min}$ in spiked rat urine and human urine, respectively (Figure 3 ).

\section{Validation results}

The calibration curve for $M G$ was linear with good correlation for both rat and human urine (Table 1). Precision and accuracy were acceptable. MG was completely recovered from urine samples. LLOQ was $0.1 \mu \mathrm{g} / \mathrm{mL}$.

\section{Application to MG excretion}

Urinary profiles of $M G$ excretion in rats receiving either $\mathrm{AE}$ alone or $\mathrm{AE}$ combined with $\mathrm{CF}$ are presented in Figure 4. MG levels after $24 \mathrm{~h}$ were below the LLOQ. After administration with $\mathrm{AE}$ alone, the amount of MG excreted during $0-24 \mathrm{~h}$ was $20.6-28.6 \%$. The amounts excreted during 0 - 8 h $(5.1-22.6 \%), 9-16$ h $(2.1-19.4 \%)$ and $17-24 \mathrm{~h}(3.1-7.1 \%)$ were not significantly different. Co-administration of $\mathrm{AE}$ and $\mathrm{CF}$ resulted to a significant increase in $M G$ excretion during $9-16 \mathrm{~h}$ and $0-24 \mathrm{~h}$, compared with $\mathrm{AE}$ alone.

\section{DISCUSSION}

Sample extraction is an important step performed prior to determine MG by using LC or GC. Liquid-liquid extraction (LLE) is a conventional method used to extract MG from rat serum [11] and plasma [6], and human urine [9]. In recent works, SPE was used to extract MG from rat and human urine [5,8,10], plasma [14], and human whole blood [15]. SPE has more advantages than LLE, despite of the higher cost. SPE not only extracts the analytes of interest but also removes the interferences in the matrices resulting to a cleaner extract. That leads to an increase in sensitivity, precision and accuracy of analysis. Additionally, it requires smaller sample volume and produces fewer waste products [16].

In this study, Oasis ${ }^{\circledR}$ HLB was used to isolate MG from urine. The cartridge is a hydrophiliclipophilic balanced sorbent which is a macroporous copolymer consisting of the lipophilic divinylbenzene and the hydrophilic $n$ vinylpyrrolidone.

It is used for retaining hydrophobic compounds containing some hydrophilic functionality, especially aromatics. It can bind basic, acidic, and neutral compounds whether polar or nonpolar. Elution can be done with intermediateand nonpolar solvents. The macroporous cartridge needs less sorbents because it produces up to five times higher capacity 
Table 1: Validation parameters (mean $\pm S D, n=5$ ) of method for determination of $M G$ in urine

\begin{tabular}{llll}
\hline Parameter & & Rat urine & Human urine \\
\hline Linearity & Range $(\mu \mathrm{g} / \mathrm{mL})$ & $0.1-10.0$ & $0.5-10.0$ \\
& Slope & $108.04 \pm 8.30$ & $107.83 \pm 7.25$ \\
& $y$-intercept & $-5.96 \pm 13.95$ & $-6.48 \pm 12.85$ \\
Precision $(\% \mathrm{CV})$ & $\mathrm{r}$ & 0.9991 & 0.9992 \\
& intra-day & $1.25-4.91$ & $0.67-3.28$ \\
Accuracy $(\% \mathrm{DEV})$ & inter-day & $1.18-5.97$ & $0.74-3.41$ \\
& intra-day & $(-) 0.32-19.64$ & $(-) 2.70-13.72$ \\
Recovery $(\%)$ & inter-day & $(-) 9.11-17.32$ & $(-) 7.20-4.88$ \\
LLOQ $(\mu \mathrm{g} / \mathrm{mL})$ & & $93.82-100.18$ & $92.74-100.83$ \\
& & 0.1 & 0.1 \\
\hline
\end{tabular}
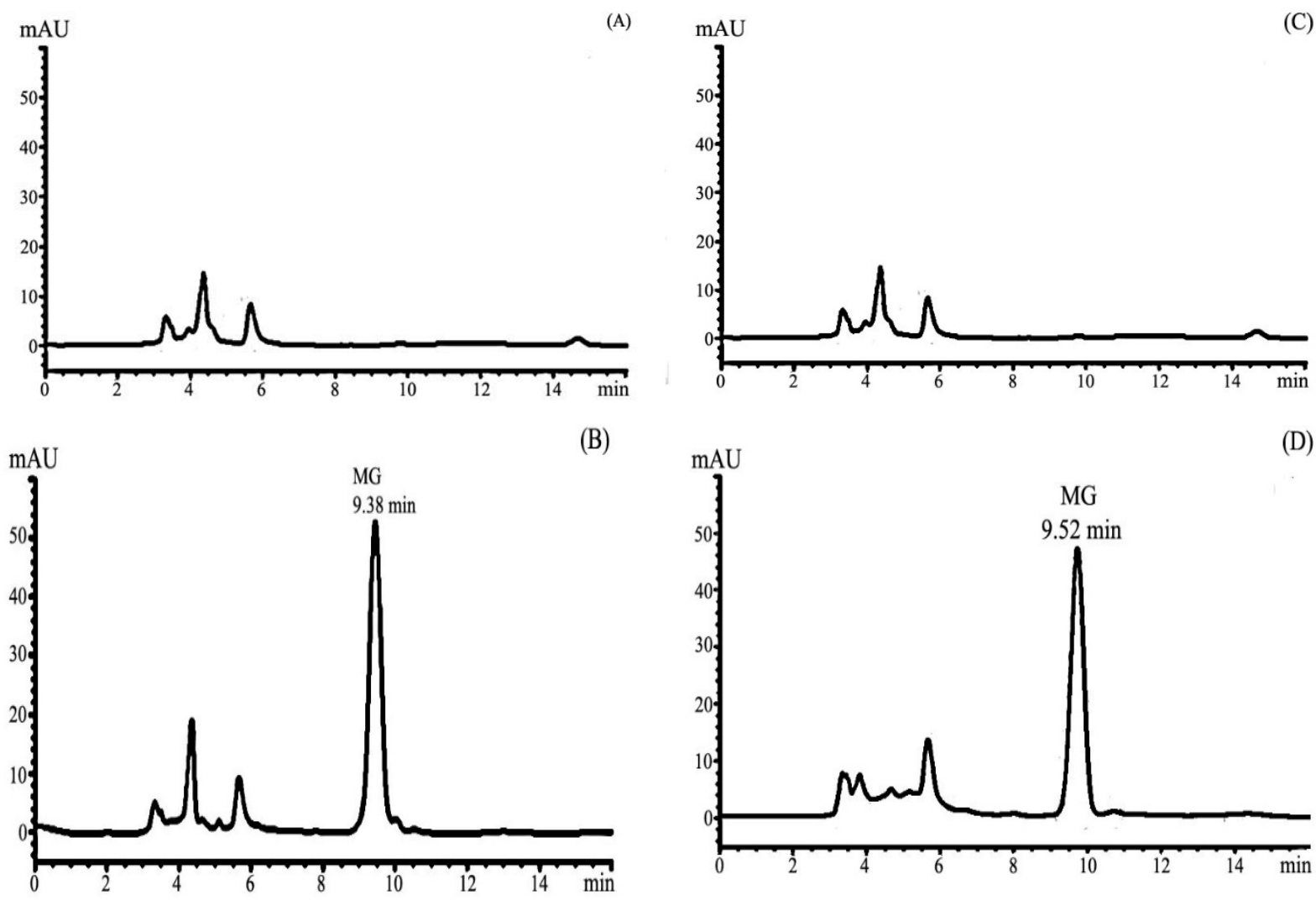

Figure 3: Chromatogram of $M G$ in spiked urine $(10 \mu \mathrm{g} / \mathrm{mL}) ;(A)$ blank rat urine; (B) spiked rat urine; (C) blank human urine; (D) spiked human urine

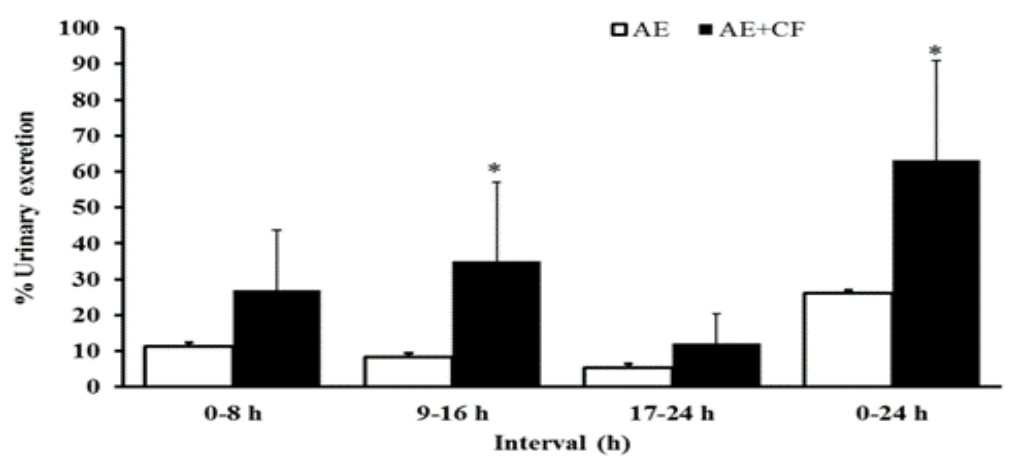

Figure 4: Urinary excretion of $M G$ (mean $\pm \mathrm{SE}, n=6)$ in rats given a single oral dose of either $\mathrm{AE}(100 \mathrm{mg} / \mathrm{kg})$ alone or $\mathrm{AE}(100 \mathrm{mg} / \mathrm{kg})$ combined with $\mathrm{CF}(25 \mathrm{mg} / \mathrm{kg})(\mathrm{AE}+\mathrm{CF}) ;{ }^{*} p<0.05$ when compared with $\mathrm{AE}$ alone 
compared to silica-based reverse phase. Additionally, it has high $\mathrm{pH}$ stability across the range of 1 to 14 and high compatibility to organic solvent. Modification of $\mathrm{pH}$ or solvent composition during washing and elution steps can easily clean the extract [17].

The SPE method was optimized by performing a wash-elute study based on two-dimensional (2D) method to investigate the percentage of methanol in washing and elution solvents while the solvent $\mathrm{pH}$ is controlled. In reversed-phase LC and SPE, the analyte retention decreases when the organic concentration increases. The retention of acidic and basic analytes is also dependent on the solvent $\mathrm{pH}$. Basic analytes are unionized at high $\mathrm{pH}$ and have high retention while they are ionized at low $\mathrm{pH}$ and exhibit low retention. In contrast, acidic analytes are ionized at high $\mathrm{pH}$ and have low retention while they are unionized at low $\mathrm{pH}$ and exhibit high retention. For neutral analytes, the retention is independent on the $\mathrm{pH}$.

MG is a weak base, with intermediate lipophilicity, poorly soluble in water and basic media, but highly soluble in acidic media [18]. After sample loading, MG interacted with the sorbent and retained in the cartridge. When a solvent mixture of $0-80 \%$ methanol-water and $2 \%$ ammonium hydroxide passed through the cartridge, MG was unionized and remained in the cartridge. Only highly- and intermediate polar compounds both acid and neutral interferences were removed. When methanol concentration increased (90 -100 \%), MG was eluted. Therefore, the mixture of $0-80 \%$ methanol-water with $2 \%$ of ammonium hydroxide was probably used as a washing solvent. The results showed that washing with low- followed by high percentage of methanol-basic mixture were preferable. The $5 \%$ methanol-water mixture with $2 \%$ ammonium hydroxide removed most polar acidic and neutral interferences while the $70 \%$ methanol-water mixture eliminated less polar compounds. That resulted to cleaner extract and lesser chromatographic noises.

MG has intermediate lipophilicity and high solubility in acid environment in which it turned into an ionized form. With intermediate polar solvent $(50 \%$ methanol mixture with $2 \%$ acetic acid), MG was initiated to elute. With $100 \%$ methanol-acid mixture, the elution was complete. Pure methanol containing $2 \%$ acetic acid was the best elution solvent. Regarding to the results, $M G$ was also eluted with $100 \%$ methanol containing $2 \%$ ammonium hydroxide, but the recovery was over $120 \%$ and the chromatogram was asymmetrical. That might be because other non-polar compounds were co-eluted and detected at the same wavelength as MG. Hence, the $100 \%$ methanol-base mixture was not chosen as the elution solvent.

The optimized SPE method was coupled with the HPLC-UV technique to determine MG in rat and human urine. All validation parameters were within the level of acceptance. The SPE method resulted to complete extraction of MG from urine (>93 \%). Previous studies employed mixedmode cation-exchange sorbent cartridges (Oasis ${ }^{\circledR}$ MCX and Isolute Confirm HCX), which was selective for basic analytes, to extract $M G$ and other compounds from rat and human urine $[5,8,10]$. However, only one study reported extraction efficiency of MG of $73 \%$ using Oasis ${ }^{\circledR}$ MCX [10]. The present study showed that the universal HLB sorbent was sufficiently sensitive and selective for extraction of $M G$ from urine.

Among the studies using SPE method, the limits of detection (LOD) of MG varied depending on detection techniques and sample volume. Philipp et al [5] extracted urine sample by using Isolute Confirm HCX before detecting MG with GC-MS and reported the LOD of $0.1 \mu \mathrm{g} / \mathrm{mL}$. However, 3 $\mathrm{mL}$ of urine was used to increase sensitivity of detection. Tang et al [10] extracted $1 \mathrm{~mL}$ of urine with Oasis ${ }^{\circledR}$ MCX before detection with UHPLCMS/MS and reported highly sensitive measurement with the LOD of $5 \mathrm{ng} / \mathrm{mL}$. Levels of $M G$ in urine of kratom users in previous reports ranged from 1 to $>50,000 \mathrm{ng} / \mathrm{mL}[1,7]$. There are no quantitative data of urinary MG in Thai kratom users. Only a prevalence study reported the presence of $M G$ in urine of $0.9 \%$ of Thai drivers with the level above $50 \mathrm{ng} / \mathrm{mL}$ [19]. The LLOQ of $0.1 \mu \mathrm{g} / \mathrm{mL}$ obtained in the present study is sufficiently and sensitively for screening most kratom users. The employment of the optimized SPE method to the more sophisticate LC technique could enhance sensitivity of detection.

Reports about an interaction between MG and other substances are rare. CF may enhance action of $M G$ or other alkaloids in kratom as indicated that an analgesic effect of $A E$ from kratom could be potentiated by co-administration of CF and codeine [20]. The concomitant use of kratom and CF may cause overstimulation or elevated blood pressure, so this should be avoided [1]. MG showed toxicokinetic interaction with permethrin [21]. A single and multiple oral pretreatment with $M G$ and kratom alkaloid extract delayed the elimination of permethrin in rats probably by inhibition of its hydrolysis, and this may increase the risk of permethrin neurotoxicity in kratom users. 
The present study shows an increase in urinary excretion of $M G$ in rats co-ingested with a single dose of CF. MG is excreted into urine as both unchanged form and various metabolites after undergoing an extensive hepatic metabolism [3]. The increased excretion is probably because CF has a diuretic effect and can increase glomerular filtration and renal blood flow especially in the renal medulla [22]. This study firstly demonstrated a pharmacokinetic alteration of MG caused by other substances.

\section{CONCLUSION}

A simple SPE method has been developed for extracting $M G$ in urine. Employing this method to HPLC-UV detection resulted in an accurate, precise and sensitive analysis. This technique is suitable for the use in forensic science laboratories, poisons control center and other units responsible for identifying narcotic substances. This study provides an alternative method for laboratories that lack high technology equipment such as LC and GC, and it is useful for studies that involve MG pharmacokinetic.

\section{DECLARATIONS}

\section{Acknowledgement}

This work received grants from Forensic Science Program, Natural Products Research Center, and Graduate School, Prince of Songkla University, Thailand. The authors are thankful to Asst Prof Dr Niwat Keawpradub, Department of Pharmacognosy and Pharmaceutical Botany for his advice about alkaloid extraction. Thanks also to Dr Brian Hodgson and Anna Chatthong for assistance with the English language.

\section{Conflict of Interest}

No conflict of interest associated with this work.

\section{Contribution of Authors}

The authors declare that this work was done by the authors named in this article and all liabilities pertaining to claims relating to the content of this article will be borne by them.

\section{Open Access}

This is an Open Access article that uses a funding model which does not charge readers or their institutions for access and distributed under the terms of the Creative Commons Attribution License (http://creativecommons.org/licenses/by/ 4.0) and the Budapest Open Access Initiative (http://www.budapestopenaccessinitiative.org/rea d), which permit unrestricted use, distribution, and reproduction in any medium, provided the original work is properly credited.

\section{REFERENCES}

1. Ulbricht $C$, Costa $D$, Dao J, Isaac $R$, Leblanc $Y C$, Rhoades J, Windsor RC. An evidence-based systematic review of kratom (Mitragyna speciosa) by the natural standard research collaboration. J Diet Suppl 2013; 10: 152-170.

2. Saingam D, Assanangkornchai S, Geater AF, Balthip Q. Pattern and consequences of krathom (Mitragyna speciosa Korth.) use among male villagers in southern Thailand: A qualitative study. Int J Drug Policy 2013; 24: 351-358.

3. Warner ML, Kaufman NC, Grundmann O. The pharmacology and toxicology of kratom: from traditional herb to drug of abuse. Int J Legal Med 2016; 130: 127138.

4. Kaewklum S, Kaewklum M, Pootrakronchai R, Tassana $U$, Wilairat $P$, Anukarahanonta $T$. Detection of mitragynine and its metabolite in urine following ingestion of leaves of Mitragyna speciosa Korth. In: Schänzer W, Geyer H, Gotzmann A, Mareck $U$, eds. Recent advances in doping analysis (13) : Proceedings of the Manfred Donike Workshop ; 23th Cologne Workshop on Dope Analysis 27th February to 4th March 2005, 2005:403-406.

5. Philipp AA, Meyer MR, Wissenbach DK, Weber AA, Zoerntlein SW, Zweipfenning PGM, Maurer $\mathrm{HH}$. Monitoring of kratom or Krypton intake in urine using GC-MS in clinical and forensic toxicology. Anal Bioanal Chem 2011; 400: 127-135.

6. Vuppala PK, Boddu SP, Furr EB, McCurdy CR, Avery $B A$. Simple, sensitive, high-throughput method for the quantification of mitragynine in rat plasma using UPLCMS and its application to an intravenous pharmacokinetic study. Chromatographia 2011; 74: 703710.

7. Le D, Goggin MM, Janis GC. Analysis of mitragynine and metabolites in human urine for detecting the use of the psychoactive plant kratom. J Anal Toxicol 2012; 36: 616-625.

8. Philipp AA, Wissenbach DK, Zoerntlein SW, Klein ON, Kanogsunthornrat $J$, Maurer $H H$. Studies on the metabolism of mitragynine, the main alkaloid of the herbal drug Kratom, in rat and human urine using liquid chromatography-linear ion trap mass spectrometry. $J$ Mass Spectrom 2009; 44: 1249-1261.

9. Lu S, Tran BN, Nelsen JL, Aldous KM. Quantitative analysis of mitragynine in human urine by high performance liquid chromatography-tandem mass spectrometry. J Chromatogr B Analyt Technol Biomed Life Sci 2009; 877: 2499-2505.

10. Tang MHY, Ching CK, Lee CYW, Lam YH, Mak TWL. Simultaneous detection of 93 conventional and 
emerging drugs of abuse and their metabolites in urine by UHPLC-MS/MS. J Chromatogr B Analyt Technol Biomed Life Sci 2014; 969: 272-284.

11. Janchawee B, Keawpradub N, Chittrakarn S, Prasettho $S$, Wararatananurak $P$, Sawangjareon K. A highperformance liquid chromatographic method for determination of mitragynine in serum and its application to a pharmacokinetic study in rats. Biomed Chromatogr 2007; 21: 176-183.

12. USFDA. Guidance for Industry: Bioanalytical Method Validation, 2001 [cited 2016 October 13]. Available from: http://www.fda.gov/downloads/Drugs/GuidanceComplian ceRegulatoryInformation/Guidances/UCM070107.pdf.

13. CIOMS and ICLAS. The International Guiding Principles for Biomedical Research Involving Animals, 2012 [cited 2016 October 15]. Available from: http://www.cioms.ch/images/stories/CIOMS/IGP2012.pd f.

14. Parthasarathy S, Ramanathan S, Ismail S, Adenan MI, Mansor SM, Murugaiyah V. Determination of mitragynine in plasma with solid-phase extraction and rapid HPLC-UV analysis, and its application to a pharmacokinetic study in rat. Anal Bioanal Chem 2010; 397: 2023-2030.

15. Carlier J, Guitton J, Romeuf L, Bévalot F, Boyer B, Fanton L, Gaillard Y. Screening approach by ultra-high performance liquid chromatography-tandem mass spectrometry for the blood quantification of thirty-four toxic principles of plant origin. Application to forensic toxicology. J Chromatogr B 2015; 975: 65-76.
16. Żwir-Ferenc A, Biziuk M. Solid phase extraction technique - Trends, opportunities and applications. Polish J Environ Stud 2006; 15: 677-690.

17. Huck CW, Bonn GK. Recent developments in polymerbased sorbents for solid-phase extraction. J Chromatogr A 2000; 885: 51-72.

18. Ramanathan S, Parthasarathy S, Murugaiyah $V$, Magosso E, Tan SC, Mansor SM. Understanding the physicochemical properties of mitragynine, a principal alkaloid of Mitragyna speciosa, for preclinical evaluation. Molecules 2015; 20: 4915-4927.

19. Ingsathit $A$, Woratanarat $P$, Anukarahanonta $T$, Rattanasiri S, Chatchaipun P, Wattayakorn K, Lim S, Suriyawongpaisal $P$. Prevalence of psychoactive drug use among drivers in Thailand: A roadside survey. Accid Anal Prev 2009; 41: 474-478.

20. Botpiboon O, Prutipanlai S, Janchawee $B$, Thainchaiwattana S. Effects of caffeine and codeine on antinociceptive activity of alkaloid extract from leaves of kratom (Mitragyna speciosa Korth). In: The 35th Congress on Science and Technology of Thailand. The Tide Resort (Bangsaen Beach), Chonburi, Thailand, 2009.

21. Srichana $K$, Janchawee $B$, Prutipanlai $S$, Raungrut $P$, Keawpradub $N$. Effects of Mitragynine and a Crude Alkaloid Extract Derived from Mitragyna speciosa Korth. on Permethrin Elimination in Rats. Pharmaceutics2015; 7: $10-26$.

22. Echeverri D, Montes FR, Cabrera M, Galán A, Prieto A. Caffeine's vascular mechanisms of action. Int $J$ Vasc Med 2010; 2010: 1-10. 